\title{
Pengaruh Pemberian Pupuk Kandang Kotoran Ayam Terhadap Pertumbuhan Anakan Pekawai (Durio kutejensis) Pada Tanah Podsolik Merah Kuning
}

\author{
H.M. Kurniawan Candra, Dedianto \\ Fakultas Pertanian Universitas Kapuas Sintang \\ Email : candra.kurniawanmuhammad@gmail.com
}

\begin{abstract}
ABSTRAK : Penelitian ini bertujuan untuk mengetahui pengaruh pemberian dan dosis pupuk kandang kotoran Ayam yang terbaik dalam mempengaruhi pertumbuhan anakan Pekawai (Durio kutejensis) pada tanah Podsolik Merah Kuning (PMK). Penelitian ini menggunakan rancangan dengan pola dasar Rancangan Acak Lengkap (RAL). Perlakuan dalam penelitian ini adalah pemberian Pupuk Kandang Kotoran Ayam yang terdiri dari 4 perlakuan yaitu tanah pada lokasi penelitian tanpa pupuk kandang kotoran Ayam (A0 atau Kontrol), 750 gram Pupuk Kandang Kotoran Ayam per anakan (A1), 1.000 gram Pupuk Kandang Kotoran Ayam per anakan (A2) dan 1.250 gram Pupuk Kandang Kotoran Ayam per anakan (A3). Hasil penelitian diketahui bahwa pemberian pupuk kandang kotoran Ayam memberikan pengaruh yang sangat signifikan terhadap pertumbuhan anakan Pekawai (Durio kutejensis) pada tanah Podsolik Merah Kuning. Dosis perlakuan yang terbaik dalam mempengaruhi pertumbuhan pertambahan jumlah daun dan tinggi anakan Pekawai adalah perlakuan A3 (1.250 gram Pupuk Kandang Kotoran Ayam per anakan), dengan rerata pertambahan jumlah daun sebanyak 17,17 helai daun dan rerata pertambahan tinggi sebesar $32,00 \mathrm{~cm}$..
\end{abstract}

Kata Kunci : Pupuk Kandang Kotoran Ayam, Pertumbuhan Anakan Pekawai dan Tanah Podsolik Merah Kuning

\section{PENDAHULUAN}

Kalimantan merupakan sumber keanekaragaman plasma nutfah dari jenis pohon tropis, baik yang utamanya sebagai penghasil kayu maupun yang menghasilkan buah.

Menurut Sabran, dkk (2003), Kalimantan perlu dipertimbangkan sebagai kawasan buah-buahan tropis. Beberapa tanaman buah-buahan banyak tumbuh di pekarangan yang pada umumnya tanpa budidaya intensif, dan sebagian adalah tanaman hutan (berada di hutan).

Kalimantan Barat yang merupakan bagian dari pulau Kalimantan juga memiliki pohon buah yang cukup beranekaragam jenisnya. Salah satu pohon penghasil buah yang terdapat di Kalimantan Barat khususnya desa Segulang Kecamatan Serawai Kabupaten Sintang yang 
Pengaruh Pemberian Pupuk Kandang Kotoran Ayam Terhad Pertumbuhan Anakan Pekawai (Durio kutejensis) Pada Tanah Podsolik Merah Kuning

cukup terkenal dan digemari oleh masyarakat adalah Pekawai (Durio kutejensis).

Untuk mendapatkan bibit yang berkualitas apalagi tumbuh pada tanah miskin hara seperti tanah Podsolik Merah Kuning, tentu diperlukan pemeliharaan yang intensif, yaitu dengan pemberian pupuk. Salah satu pupuk yang dapat digunakan untuk keperluaan budidaya adalah pupuk kandang kotoran Ayam. Pupuk ini dipilih karena ramah terhadap lingkungan dan mengandung unsur hara makro dan mikro yang dibutuhkan untuk tumbuh dan berkembangnya suatu tanaman. Adapun tujuan dilakukannya penelitian ini adalah untuk :

1. Mengetahui pengaruh pupuk kandang kotoran Ayam terhadap pertumbuhan anakan Pekawai (Durio kutejensis) pada tanah Podsolik Merah Kuning.

2. Mengetahui dosis pupuk kandang kotoran Ayam yang terbaik dalam mempengaruhi pertumbuhan anakan Pekawai (Durio kutejensis) pada tanah Podsolik Merah Kuning

\section{METODOLOGI PENELITIAN}

\section{A. Rancangan Penelitian}

Rancangan yang digunakan dalam penelitian ini adalah rancangan dengan pola dasar Rancangan Acak Lengkap (RAL) Perlakuan dalam penelitian ini adalah pemberian Pupuk Kandang Kotoran Ayam yang terdiri dari 4 perlakuan yaitu tanah pada lokasi penelitian tanpa pupuk kandang kotoran Ayam (A0 atau Kontrol), 750 gram Pupuk Kandang Kotoran Ayam per anakan (A1), 1.000 gram Pupuk Kandang Kotoran Ayam per anakan (A2) dan 1.250 gram Pupuk Kandang Kotoran Ayam per anakan (A3). Rancangan ini dipilih karena anakan Pekawai memiliki tinggi dan jumlah daun yang sama dan alat penelitian yang digunakan relatif seragam (homogen).

\section{B. Populasi dan Sampel}

Populasi dalam penelitian ini adalah semua anakan Pekawai yang digunakan dari seluruh perlakuan yaitu 4 perlakuan x 6 ulangan $\mathrm{x} 4$ anakan $=96$ anakan. Sampel diambil secara acak sebanyak 2 anakan dari setiap perlakuan, sehingga jumlah 
Pengaruh Pemberian Pupuk Kandang Kotoran Ayam Terhad Pertumbuhan Anakan Pekawai (Durio kutejensis) Pada Tanah Podsolik Merah Kuning

sampel pada penelitian ini adalah 4 x 6 × $2=48$ anakan.

\section{Bahan dan Alat}

Bahan yang digunakan dalam penelitian ini adalah Anakan Pekawai dengan tinggi $15 \mathrm{~cm}$, dan jumlah daun 5 helai, Pupuk Kandang Kotoran Ayam, Tanah Podsolik Merah Kuning, Air, Polybag ukuran $20 \times 20 \times 20 \mathrm{~cm}$ dan Daun AlangAlang. Adapun alat-alat yang digunakan dalam penelitian ini adalah Parang, sabit dan cangkul, Gembor, Kamera, Alat tulis/buku, Mistar ukur, Spidol permanen, Timbangan, Kayu dan papan.

\section{Pelaksanaan Penelitian}

1. Pembuatan Naungan

Naungan dibuat dengan menggunakan daun alang-alang. Adanya naungan dimaksudkan untuk menghindari sinar matahari dan hujan secara langsung. Naungan dibuat dengan bagian sebelah timur yang lebih tinggi daripada sebelah barat, yang memiliki panjang 3,5 m dan lebar 2,5 m. Sebelum naungan dibuat, terlebih dahulu dilakukan pembersihan di daerah sekitar naungan. Selanjutnya permukaan tanah yang kurang datar diratakan, agar polybag yang diletakkan dapat berdiri dengan tegak.

2. Penyiapan Media Tanam

Media tanam berupa tanah diambil langsung dari tanah yang berada di lokasi penelitian. Tanah diambil mengunakan cangkul, dihaluskan/dihancurkan dan digemburkan. Media tanam yang telah dihancurkan, kemudian dikering anginkan selama kurang lebih 1 minggu agar mempermudah proses penggemburan. Setelah media digemburkan sampai benar - benar merata, kemudian dimasukkan kedalam polybag sebanyak \pm 1.000 gram.

3. Pemilihan Anakan Pekawai

Anakan Pekawai yang digunakan dalam penelitian ini adalah anakan hasil pemilihan di alam, dengan kriteria jumlah daun dan tinggi yang relatif sama. Setiap anakan mempunyai 5 helai daun dan tinggi $15 \mathrm{~cm}$. Anakan diambil dengan cara putaran dengan membawa serta tanah sebagai tempat tumbuhnya. 
Pengaruh Pemberian Pupuk Kandang Kotoran Ayam Terhad Pertumbuhan Anakan Pekawai (Durio kutejensis) Pada Tanah Podsolik Merah Kuning

4. Pupuk Kandang Kotoran Ayam

Pupuk Kandang Kotoran Ayam didapatkan dari toko pertanian. Pupuk Kandang Kotoran Ayam yang digunakan adalah yang telah matang. Selanjutnya pupuk kandang kotoran Ayam dicampur/diaduk secara merata dengan tanah sebagai media tumbuh anakan Pekawai, dengan perlakuan sebagai berikut ;

A0 : Tanah pada lokasi penelitian tanpa Pupuk Kandang Kotoran Ayam (Kontrol)

A1 :750 gram Pupuk Kandang Kotoran Ayam per anakan

A2 : 1.000 gram Pupuk Kandang Kotoran Ayam per anakan A3 : 1.250 gram Pupuk Kandang Kotoran Ayam per anakan

Pemupukan hanya diberikan sekali selama penelitian, yaitu pada saat menyiapkan media tanam, dengan cara mencampurkan Pupuk Kandang Kotoran Ayam dengan media tanam secara merata sesuai dosis yang telah ditentukan.

\section{Penanaman}

Anakan Pekawai yang telah dipilih dengan kriteria jumlah daun dan tinggi yang seragam diambil satu persatu dan langsung ditanam pada media yang telah disiapkan. Penanaman dilakukan dengan cara memindahkan anakan secara hatihati selanjutnya melubangi media tanam dan menanamkan bibit secara tegak pada media di dalam polybag. Setelah anakan dimasukan ke dalam lubang tanam kemudian ditutup kembali dan disiram dengan sedikit air. Penanaman dilakukan pada pagi hari sekitar jam 06.00 WIB sampai selesai.

6. Pemeliharaan

Pemeliharaan dilakukan meliputi pencabutan rumput dan gulma pada media tanam anakan Pekawai, serta dilakukan penyiraman secara rutin setiap pagi dan sore hari kecuali jika terjadi hujan, maka tidak dilakukan penyiraman.

\section{HASIL DAN PEMBAHASAN}

\section{A. Hasil Penelitian}

\section{A.1. Pertambahan Jumlah Daun Anakan Pekawai (Helai)}

Pertambahan jumlah daun anakan Pekawai merupakan hasil penghitungan terhadap seluruh jumlah daun yang tumbuh secara 
Pengaruh Pemberian Pupuk Kandang Kotoran Ayam Terhad Pertumbuhan Anakan Pekawai (Durio kutejensis) Pada Tanah Podsolik Merah Kuning

sempurna, termasuk daun yang telah gugur selama penelitian.

Berdasarkan hasil analisis sidik ragam,diketahui bahwa perlakuan yang diberikan memberikan pengaruh yang sangat signifikan terhadap pertambahan jumlah daun anakan Pekawai. Sesuai hasil analisis sidik ragam yang menunjukkan adanya pengaruh yang sangat signifikan, maka dilakukan uji lanjut untuk mengetahui perlakuan mana yang terbaik dalam mempengaruhi pertambahan jumlah daun anakan Pekawai. Uji lanjut dilakukan melalui Uji Beda Nyata Terkecil (BNT).

Berdasarkan hasil uji BNT, diketahui bahwa perlakuan A3 (1.250 gram Pupuk Kandang Kotoran Ayam per anakan) adalah yang terbaik dibandingkan dengan seluruh perlakuan lainnya. Perlakuan A3 berbeda sangat signifikan dibandingkan dengan perlakuan A2 (1.000 gram Pupuk Kandang Kotoran Ayam per anakan), berbeda sangat signifikan dengan perlakuan A1 (750 gram Pupuk Kandang Kotoran Ayam per anakan) dan berbeda sangat signifikan terhadap perlakuan A0 (kontrol/tanpa pupuk kandang kotoran Ayam). Perlakuan A3 telah mampu memacu pertambahan jumlah daun anakan Pekawai yang tertinggi, yaitu dengan rerata pertambahan jumlah daun sebanyak 17,17 helai daun. Sedangkan perlakuan A2 rerata pertambahan jumlah daun sebanyak 14,17 helai daun, perlakuan A1 rerata pertambahan jumlah daun sebanyak 12,40 helai daun dan A0 (kontrol) dengan rerata pertambahan jumlah daun sebanyak 9,67 helai daun.

\section{A.2. Pertambahan Tinggi Anakan} Pekawai (cm)

Pertambahan tinggi anakan Pekawai merupakan hasil pengukuran tinggi batang yang dimulai dari pangkal batang $\pm 2 \mathrm{~cm}$ di atas media tanam, sampai titik tumbuh tertinggi. Berdasarkan hasil analisis sidik ragam, diketahui bahwa perlakuan yang diberikan memberikan pengaruh yang sangat signifikan terhadap pertambahan tinggi anakan Pekawai. Sesuai hasil analisis sidik ragam yang menunjukkan adanya pengaruh yang 
Pengaruh Pemberian Pupuk Kandang Kotoran Ayam Terhad Pertumbuhan Anakan Pekawai (Durio kutejensis) Pada Tanah Podsolik Merah Kuning

sangat signifikan, maka dilakukan uji lanjut untuk mengetahui perlakuan mana yang terbaik dalam mempengaruhi pertambahan tinggi anakan Pekawai. Uji lanjut dilakukan melalui Uji Beda Nyata Terkecil (BNT).

Berdasarkan hasil uji BNT, diketahui bahwa perlakuan A3 (1.250 gram Pupuk Kandang Kotoran Ayam per anakan) adalah yang terbaik dibandingkan dengan seluruh perlakuan lainnya. Perlakuan A3 berbeda sangat signifikan dibandingkan dengan perlakuan A2 (1.000 gram Pupuk Kandang Kotoran Ayam per anakan), berbeda sangat signifikan dengan perlakuan A1 (750 gram Pupuk Kandang Kotoran Ayam per anakan) dan berbeda sangat signifikan terhadap perlakuan A0 (kontrol/tanpa pupuk kandang kotoran Ayam). Perlakuan A3 telah mampu memacu pertambahan tinggi anakan Pekawai yang tertinggi, yaitu dengan rerata pertambahan tinggi sebesar 32,00 cm. Sedangkan perlakuan A2 dengan rerata pertambahan tinggi sebesar 25,17 cm, perlakuan A1 dengan rerata pertambahan tinggi sebesar
$18,83 \mathrm{~cm}$ dan A0 (kontrol) dengan rerata pertambahan tinggi sebesar $15,33 \mathrm{~cm}$.

\section{B. Pembahasan}

Berdasarkan hasil analisis sidik ragam terhadap seluruh parameter pengamatan, yaitu pertambahan jumlah daun dan pertambahan tinggi anakan sebagaimana terlihat pada bagian hasil penelitian, diketahui bahwa pemberian pupuk kandang kotoran Ayam memberikan pengaruh yang sangat signifikan terhadap pertumbuhan anakan Pekawai pada tanah Podsolik Merah Kuning. Hasil ini mengindikasikan bahwa pupuk kandang kotoran Ayam yang diberikan telah dapat dimanfaatkan oleh anakan Pekawai, sehingga terjadi pertumbuhan pada anakan tersebut. Hal ini sesuai dengan pendapat Sigit dan Paulus (2008), Pupuk kandang kotoran ayam mengandung unsur hara paling kaya dibandingkan dengan unsur hara pupuk kandang dari hewan lain. Kotoran ayam mengandung unsurunsur hara seperti $\mathrm{N}, \mathrm{P}$, dan $\mathrm{K}$. Ketiga unsur N, P dan K mempunyai peran yang sangat penting terhadap 
Pengaruh Pemberian Pupuk Kandang Kotoran Ayam Terhad Pertumbuhan Anakan Pekawai (Durio kutejensis) Pada Tanah Podsolik Merah Kuning

pertumbuhan dan reproduksi tanaman, dimana ketiga unsur ini saling berinteraksi satu sama lain dalam menunjang pertumbuhan tanaman

Berdasarkan hasil uji lanjut melalui uji BNT, diketahui bahwa perlakuan yang terbaik dalam mempengaruhi pertambahan jumlah daun dan pertambahan tinggi anakan Pekawai adalah perlakuan A3 (1.250 gram Pupuk Kandang Kotoran Ayam per anakan). Perlakuan A3 terbukti mampu memacu pertambahan jumlah daun yang terbanyak, yaitu sebanyak 17,17 helai daun dan memacu pertambahan tinggi anakan Pekawai yang paling tinggi dibanding perlakuan lainnya yaitu 32 $\mathrm{cm}$. Perlakuan A3 berbeda sangat signifikan dibandingkan dengan perlakuan A2 (1.000 gram Pupuk Kandang Kotoran Ayam per anakan), berbeda sangat signifikan juga dengan perlakuan A1 (750 gram Pupuk Kandang Kotoran Ayam per anakan) dan berbeda sangat signifikan dibandingkan dengan perlakuan A0 (kontrol/tanpa pupuk).

Pertambahan bagian vegetatif tanaman, baik berupa jumlah daun maupun tinggi, memberikan makna bahwa telah terjadi pertumbuhan pada tanaman tersebut. Pertambahan jumlah daun dan tinggi berarti telah terjadi pembelahan sel pada bagaian tersebut, sehingga batang tanaman menjadi bertambah tinggi dan jumlah daun menjadi lebih banyak. Hasil penelitian yang menunjukkan adanya pengaruh sangat signifikan oleh pemberian pupuk kandang kotoran Ayam terhadap pertambahan jumlah daun dan tinggi anakan Pekawai, mengindikasikan bahwa pupuk yang diberikan telah dapat dimanfaat oleh anakan Pekawai dengan baik, sehingga pertumbuhan terjadi secara optimal.

Pemberian pupuk kandang kotoran Ayam pada media tanam dimaksudkan untuk memperbaiki sifat fisik dan kimia tanah. Pupuk kandang kotoran Ayam merupakan salah satu pupuk organik yang ramah terhadap lingkungan, meski diberi dalam jumlah yang banyak pupuk ini tidak berakibat racun bagi tanaman. Pemberian pupuk kandang kotoran ayam berfungsi untuk memperbaiki sifat fisika seperti struktur, permeabilitas dan pori-pori, 
Pengaruh Pemberian Pupuk Kandang Kotoran Ayam Terhad Pertumbuhan Anakan Pekawai (Durio kutejensis) Pada Tanah Podsolik Merah Kuning

konsistensi dan sifat kimia seperti sifat kapasitas tukar kation, hara dan biologi tanah, selain itu juga meningkatkan organisme mikro tanah. Pupuk kandang didalam tanah mempunyai pengaruh terhadap fisik tanah, pengaruh tersebut berupa penguraian yang dapat mempertinggi kadar bunga tanah (humus). Pupuk kandang yang diberikan secara teratur kedalam tanah, dapat membentuk bunga-bunga tanah yang dapat meningkatkan daya penahan air, Sehingga memudahkan akar-akar tanaman menyerap zat-zat makanan bagi pertumbuhan dan perkembangannya.

$$
\text { Perlakuan A3 (1.250 gram }
$$

Pupuk Kandang Kotoran Ayam per anakan) yang merupakan perlakuan terbaik dalam memacu pertumbuhan anakan Pekawai, adalah dosis perlakuan tertinggi. Terhadap kondisi ini, memberikan gambaran terdapat kecenderungan bahwa, semakin banyak pupuk kandang kotoran Ayam yang diberikan, maka semakin baik pertumbuhan anakan Pekawai. Hal ini juga menjelaskan bahwa dalam penelitian ini belum didapat dosis pupuk kandang kotoran Ayam yang maksimal bagi kebutuhan pertumbuhan anakan Pekawai.

\section{KESIMPULAN DAN SARAN}

\section{Kesimpulan}

Berdasarkan hasil penelitian dan analisis data yang telah dilakukan mengenai pengaruh pemberian pupuk kandang kotoran Ayam terhadap pertumbuhan anakan Pekawai pada tanah Podsolik Merah Kuning, maka dapat disimpulkan sebagai berikut;

1. Pemberian pupuk kandang kotoran Ayam memberikan pengaruh yang sangat signifikan terhadap pertumbuhan anakan Pekawai (Durio kutejensis) pada tanah Podsolik Merah Kuning

2. Dosis perlakuan yang terbaik dalam mempengaruhi pertumbuhan pertambahan jumlah daun dan tinggi anakan Pekawai adalah perlakuan A3 (1.250 gram Pupuk Kandang Kotoran Ayam per anakan), dengan rerata pertambahan jumlah daun sebanyak 17,17 helai daun dan rerata pertambahan tinggi sebesar $32,00 \mathrm{~cm}$. 
Pengaruh Pemberian Pupuk Kandang Kotoran Ayam Terhad Pertumbuhan Anakan Pekawai (Durio kutejensis) Pada Tanah Podsolik Merah Kuning

Saran

Sehubungan dengan hasil penelitian yang menunjukkan bahwa semakin tinggi dosis perlakuan yang diberikan semakin baik pertumbuhan anakan Pekawai dan belum diketahui dosis perlakuan yang maksimal bagi pertumbuhan anakan Pekawai, maka dipandang perlu dilakukan kajian lebih lanjut berupa penambahan dosis pupuk yang digunakan agar didapat dosis yang maksimal bagi tumbuh dan berkembangnya anakan Pekawai secara optimal.

\section{DAFTAR PUSTAKA}

Antarlina, S. S. 2009. Karakterisasi Sifat Fisik Dan Kimia Buah - Buahan Lokal Kalimantan. Buletin Plasma Nutfah.

Hanafiah, KA. 2008. Rancangan Percobaan. Jakarta : PT. Raja Grafindo Persada.

Hardjowigeno, S. 2003. Ilmu Tanah. Jakarta. Akademika Pressindo.

Heyne K. 1987. Tumbuhan Berguna Indonesia III. Jakarta (ID): Yayasan Sarana Wana Jaya.
Iskandar. 2017. Pengaruh Pemberian

Top Soil Dan Pupuk Kandang Kotoran Ayam Terhadap Pertumbuhan Anakan Kelampai (Elateriospermum Tapos) Di Persemaian. Skripsi. Jurusan Kehutanan. Fakultas Pertanian Universitas Kapuas Sintang. Sintang. Kalimantan Barat.

Lingga. P. 1991. Jenis dan Kandungan Hara pada Beberapa Kotoran Ternak. Pusat Pelatihan Pertanian dan Pedesaan Swadaya (P4S) ANTANAN. Bogor.

Salma I. 2011. Durio of Malaysia. MARDI. Kuala Lumpur.

Setiawan A.I. 2008. , Manfaat Kotoran Ternak. Penebar Swadaya. Jakarta

Siregar, M. 2006. Review: Species Diversity of Local Fruit Trees in Kalimantan: Problems of Conservation and Its Development. Biodiversitas.

Uji, T. 2005. Keanekaragaman Jenis dan Sumber Plasma Nutfah Durio (Durio spp.) di Indonesia. Bulletin Plasma Nutfah. 